\title{
CONSEQÜÊ NCIAS DE DIFERENTES SISTEMAS DE PREPARO DO SOLO SOBRE A CONTAMINAÇÃO DO SOLO, SEDIMENTOS E ÁGUA POR METAIS PESADOS ${ }^{(1)}$
}

\author{
J . E. V. NÚÑEZ(2), N. M. B. AMARAL SOBRINHO(3), \\ F. PALMIERI ${ }^{(4)}$ \& A. A. MESQUITA ${ }^{(5)}$
}

\begin{abstract}
RESUMO
Este trabalho teve por objetivos determinar a influência de diferentes métodos de preparo do solo sobre as perdas por erosão de metais pesados e avaliar a contaminação dos sedimentos e da água do córrego principal da microbacia de Caetés, município de Paty do Alferes (RJ ). A avaliação foi realizada durante os meses de dezembro de 1996 a março de 1997, no ciclo de cultivo do pepino (Cucumis sativus L.). Foram utilizadas parcelas do tipo Wischmeier, de tamanho de 22,0 x 4,0 m. Os tratamentos utilizados foram os seguintes: (a) aração com trator morro abaixo e quei mado (MAQ); (b) aração com trator morro abaixo não quei mado com restos de vegetação natural entre as linhas (MANQ); (c) aração com tração animal em nível, faixas de capim-colonião a cada 7,0 m (AA), e (d) cultivo mínimo, com preparo de covas em nível (CM). Avaliaram-se também os teores desses metais nos sedimentos de fundo e na água do córrego principal que drena a microbacia de Caetés. As perdas mais elevadas de metais pesados por erosão foram verificadas no tratamento MAQ, típico da região. Os sedimentos e a água do córrego da microbacia de Caetés mostraram incrementos nos teores totais de $\mathrm{Cd}, \mathrm{Ni}, \mathrm{Pb}, \mathrm{Zn}$ e $\mathrm{Mn}$ de acordo com a posição de coleta na área. A água coletada no córrego e no açude apresentou concentrações de $\mathrm{Cd}$, Mn e Pb acima dos padrões máximos estabelecidos para água potável. Os resultados obtidos neste trabalho permitem concluir que o uso intensivo de agroquímicos e as elevadas perdas de solo por erosão podem acarretar sérios riscos de contaminação da água do córrego da microbacia que é utilizada pelos ani mais e para irrigação.
\end{abstract}

Termos de indexação: erosão, agroquímicos, $\mathrm{Cd}, \mathrm{Ni}, \mathrm{Pb}, \mathrm{Zn}, \mathrm{Mn}$.

(1) Parte da Tese de Mestrado do primeiro autor, apresentada ao Departamento de Solos da Universidade Federal Rural do Rio de J aneiro - UFRRJ , Seropédica (RJ ). Pesquisa realizada com recursos da União Européia e Ciamb-PADCT/FINEP. Recebido para publicação em abril de 1998 e aprovado em junho de 1999.

(2) Pesquisador do Instituto de Investigación Agropecuaria do Panamá (IDIAP). Apartado 58, Santiago, Província de Veraguas.

(3) Professor do Departamento de Solos, Universidade Federal Rural do Rio de J aneiro (UFRRJ ). CEP 23851-970 Seropédica (RJ). Bolsista do CNPq.

(4) Pesquisador da Embrapa Solos, Rua J ardim Botânico, 1024. CEP 22460-000 Rio de J aneiro (RJ ).

(5) Bolsista de Iniciação Científica do CNPq. 


\title{
SUMMARY: INFLUENCE OF DIFFERENT SOIL TILLAGE METHODS ON THE CONTAMINATION OF SOILS, SEDIMENTS AND WATER BY HEAVY METALS
}

\begin{abstract}
The objectives of this study were to determine the influence of different soil tillage methods on thel oss of heavy metals by erosion, and to evaluatethelevel of contami nation in sediments and water from themain stream in Caetés watershed, Paty do Alferes County, Rio deJ aneiro. Theexperiment was conducted from December 1996 to March 1997, and cucumber (Cucumis sativus L.) was the cultivated crop. Four Wichmeier pl ots wereinstalled, with an area of $22 \times 4 \mathrm{~m}$. Thefol lowing treatments wereused: (a) tillagewith machinery and operation down hill and burning of the grassland (MAQ); (b) tillage with machinery and operation down and without burning of grassland between lines of crop (MANQ); (c) tillagewith animal traction and following the natural contour of the hill, strip cropping grass each $7 \mathrm{~m}$ (AA); and minimum tillage(CM). Heavy metal concentrations wereal so determined in thesamples of sediments and water from themain Caetés watershed stream. Thehighest losses of heavy metals by erosi on were in the MAQ treatment. The bottom stream sediments showed an increase in the total concentration of $\mathrm{Cd}, \mathrm{Ni}, \mathrm{Pb}, \mathrm{Zn}$ and $\mathrm{Mn}$, according to the sampling position, upstream and downstream, showed $\mathrm{Cd}, \mathrm{Mn}$ and $\mathrm{Pb}$ concentration above the maximum limits establ ished for tap water. Theresults obtai ned al lowed to concludethat the intensive use of agrochemicals associated with thehigh soil losses by erosion can determine serious risks of contamination of the water from the main stream in Caetés watershed, which is used by animals and for irrigation.
\end{abstract}

Index terms: erosion, agrochemicals, $\mathrm{Cd}, \mathrm{Ni}, \mathrm{Pb}, \mathrm{Zn}, \mathrm{Mn}$.

\section{NTRODUÇÃO}

A aplicação de insumos agrícolas aos solos e culturas tornou-se uma prática comum na agricultura. Os principais objetivos do uso desses agroquímicos são o aumento do suprimento de nutrientes e correção do pH do solo (fertilizantes e corretivos) e a proteção das lavouras pelo controle de patógenos e pragas (agrotóxicos). Essas práticas podem, entretanto, causar degradação química do solo, como resultado da acumulação de el ementos e, ou, compostos em níveis indesejáveis.

Os fertilizantes, como não são suficientemente purificados durante o processo de manufatura, por razões econômicas, geralmente contêm diversas impurezas, entre elas os metais pesados (Amaral Sobrinho et al., 1992). Esses metais, freqüentemente, fazem parte dos componentes ativos dos pesticidas (Frank et al., 1976), sendo, segundo vários autores, a adição desses elementos nos solos agrícolas causada pel o uso repeti do e excessivo de fertilizantes, pesticidas metálicos e resíduos orgânicos (KabataPendias \& Pendias, 1984; Tiller, 1989; Alloway, 1990; Blume \& Brümmer, 1991; Gimeno-Garcia et al., 1996).

Segundo van Put et al. (1994), os metais pesados presentes no material de solo perdido por erosão, quando atingirem cursos d'água, poderãoser liberados com mudanças de certas condições físico-químicas do meio, tais como: pH, potencial de oxirredução e força iônica. Segundo esses pesquisadores, os processos de oxirredução e o pH são os mais importantes nas mudanças de solubilidade desses metais adsorvidos na superfície de óxidos de Fe e Mn, que são fases do sol o passíveis de sofrer redução, podendo ser liberados ao sofrerem mudanças no potencial redox, tornando-se, por isso, perigosos nessas condições redutoras (Pardo et al., 1990). Entretanto, a solubilidade dos metais pesados existentes nos sedimentos de rios, ao serem depositados na superfície do solo, dependerá da facilidade com que esses metais possam sofrer remobilização. Portanto, sob condições de oxidação, a solubilidade dos metais pesados dos sedimentos de rios pode ser reduzida, ocorrendo mudanças através da passagem gradual desses elementos ligados a sulfetos metálicos para carbonatos, oxidróxidos, óxidos ou silicatos. As frações trocáveis eligadas a carbonato poderãoli berar os metais mais facilmente por efeito da diminuição do pH (Alloway, 1990).

O município de Paty do Alferes, localizado na região serrana do estado do Rio de J aneiro, tem, exclusivamente, a agricultura como atividade econômica. Lá são produzidos cerca de $40 \%$ de todo o tomate do estado do Rio de J aneiro e grande percentual de outras olerícolas, tais como: repolho, pepino, vagem, pimentão, etc. Na última década, apesar dos altos investimentos, a produção agrícola 
vem decrescendo em virtude de problemas, tais como: desmatamento ocorrido no decorrer dos anos; utilização de práticas não adequadas às condições edafoclimáticas; realização de $90 \%$ das atividades agrícol as em encostas com decl ividade média de $45 \%$, e com preparo do solo feito morro abaixo, sem utilização de práticas conservacionistas. O uso abusivo e indiscriminado de pesticidas (inseticidas, fungicidas, herbicidas e outros) pode ter concorrido para o desequilíbrio do ecossistema, aumentando, assim, a incidência de pragas e doenças (Gravena et al., 1998).

Ramalho (1996), avaliando a influência da topografia e do uso agrícola sobre o acúmulo de metais pesados na microbacia de Caetés, município de Paty do Alferes, verificou que, nas áreas exploradas com ol ericultura por cerca de 15 anos, a declividade teve um efeito marcantena acumulação desses metais. As menores concentrações desses elementos foram encontradas nas toposseqüências de pendente curta e maior declividade. Esse pesquisador levantou a hipótese dequea erodibilidade das áreas de maior declividade tinha grande influência na menor acumulação, considerando as maiores perdas desses metais por erosão.

A adoção de práticas de preparo do solo pouco recomendáveis para áreas susceptíveis à erosão e a aplicação de el evada quantidade de agroquímicos podem resultar em fortes impactos ao ambiente. A perda de solo por erosão poderá, dessa forma, contribuir para a contaminação dos corpos d'água que são utilizados na microbacia como fonte de água para os animais e irrigação. Sistemas de preparo do solo que reduzam as perdas por erosão deverão também diminuir os riscos de contaminação dos corpos d'água com metais pesados.

Diante do exposto, este trabalho pretendeu: avaliar a influência do tipo de preparo do solo na quantidade de metais pesados perdidos por erosão e na distribuição desses elementos nas diferentes formas químicas e avaliar a contaminação do solo, água esedimentos por metais pesados na mi crobacia de Caetés (Paty do Alferes-RJ ).

\section{MATE RIAL E MÉTODOS}

Neste trabalho, utilizou-se um experimento desenvolvido por Kunzmann et al. (1998), com o auxílio da Embrapa Solos. O experimento foi realizado em parcelas dotipo Wischmeier, instaladas numa área da microbacia de Caetés, em 1995, sobre Podzólico Vermel ho-Amarelo latossólico textura argila arenosa/argilosa com declividade em torno de $60 \%$, no município de Paty do Alferes (RJ ), para avaliar, em sucessivos cultivos, perdas de solo causadas pelas chuvas. As culturas utilizadas, as épocas de plantio e col heita, as perdas de solo por parcela e os insumos agrícol as com suas respectivas quantidades aplicadas, desdeo início do experimento, encontram-se no quadro 1. N o quadro 2, encontramse as quantidades dos metais $\mathrm{Zn}, \mathrm{Cd}, \mathrm{Pb}, \mathrm{Mn}$ e $\mathrm{Ni}$ adicionados nos quatrocid os decultivo, desdeo início do experimento, calculados com base nas concentrações dos metais pesados nos insumos utilizados (Quadro 3) e nas quantidades aplicadas em cada ciclo (Quadro 1).

Os tratamentos utilizados foram: (a) MAQ: aração com trator morro abaixo e restos vegetais queimados (preparo típico da região); (b) MANQ: aração com trator morro abaixo erestos vegetais não queimados; (c) AA: aração com tração animal em nível, faixas de capim-colonião a cada $7 \mathrm{~m}$, e (d) CM: cultivo mínimo com preparação de covas em nível.

O delineamento experimental foi o de blocos ao acaso com três repetições, totalizando 12 unidades experimentais. Nestetrabal ho, os tratamentos serão designados utilizando as siglas correspondentes para identificar cada um deles.

As adubações e os controles fitossanitários realizados foram os mesmos em todos os tratamentos e, para este estudo, foram monitoradas apenas as perdas de metais pesados ocorridas durante o ciclo do pepino (Cucumis sativus L.).

Col etaram-se, em todos os tratamentos, antes do plantio e depois da colheita, 20 amostras simples para formar uma amostra composta de terra da camada arável $(0-20 \mathrm{~cm})$. E ssa amostra foi analisada para metais pesados, utilizando método descrito em Amaral Sobrinho et al. (1998).

O solo e a água perdidos por erosão foram armazenados em dois tanques col etores, conectados em série, e instalados no final de cada parcela. Após cada chuva, os sedimentos armazenados foram homogeneizados, o volume anotado, uma alíquota de volumeconhecidofoi col etada, seca em estufa com circulação de ar forçada a $60^{\circ} \mathrm{C}$, e o material de solo pesado ea quantidade perdida por erosão cal culada. Ao final do ciclo do pepino, as amostras de cada parcela, col etadas após cada chuva, foram misturadas em quantidades proporcionais às perdas totais calculadas no período, obtendo-se uma amostra composta de material perdido por erosão por parcela.

A pós a secagem, as amostras de sol o col etadas e as perdidas por erosão foram destorroadas, homogeneizadas e passadas através de uma peneira de $2 \mathrm{~mm}$, sendo, em seguida, trituradas em al mofariz deágata e guardadas em sacos plásticos para análise.

Avaliaram-se os teores de metais pesados nos sedimentos defundo do córrego princi pal, que drena a microbacia de Caetés. Foram coletadas 30 subamostras de volume de $10 \mathrm{~cm}^{3}$, a $20 \mathrm{~cm}$ de profundidade, no mês de março de 1997, para compor cada amostra composta, em três repetições, à montante (córrego 1) e à jusante (córrego 2) da área agrícola atual, e no açude onde desemboca esse 
Quadro 1. Culturas utilizadas, épocas de plantio e colheita, perdas de solo por tratamento e insumos agrícolas com suas quantidades aplicadas, desde $o$ início do experimento

\begin{tabular}{|c|c|c|c|c|c|}
\hline Cultura & Período & Insumos & Quantidade aplicada & Preparo do solo & Perda de solo \\
\hline & & & $\mathrm{kg} \mathrm{ha}^{-1}$ & & t ha-1 \\
\hline Tomate & $\begin{array}{l}\text { Outubro } 95 \\
\text { J aneiro } 96\end{array}$ & $\begin{array}{l}\text { Esterco de curral } \\
\text { Cama de ave } \\
\text { Torta de mamona } \\
\text { Termofosfato } \mathrm{Yoorin} \\
\mathrm{KCl}+\left(\mathrm{NH}_{4}\right)_{2} \mathrm{SO}_{4(1: 1)} \\
\text { Captan } \\
\text { Mancozeb } \\
\text { Tamaron } \mathrm{BR} \\
\text { Permetrina } \\
\text { Parathion metil }\end{array}$ & $\begin{array}{c}26.200 \\
7.500 \\
1.670 \\
700 \\
401 \\
3 \\
29 \\
5 \\
2,5 \\
25\end{array}$ & $\begin{array}{l}\text { MAQ } \\
\text { MANQ } \\
\text { AA } \\
\text { CM }\end{array}$ & $\begin{array}{l}5,54 \\
1,93 \\
0,18 \\
0,11\end{array}$ \\
\hline Vagem & $\begin{array}{l}\text { J aneiro } 96 \\
\text { Maio } 96\end{array}$ & $\begin{array}{l}\text { Esterco de curral } \\
\text { Cama de ave } \\
\text { Termofosfato Yoorin } \\
\mathrm{KCl}+\left(\mathrm{NH}_{4}\right)_{2} \mathrm{SO}_{4(1: 1)}\end{array}$ & $\begin{array}{r}46.000 \\
2.500 \\
700 \\
600\end{array}$ & $\begin{array}{l}\text { MAQ } \\
\text { MANQ } \\
\text { AA } \\
\text { CM }\end{array}$ & $\begin{array}{l}6,07 \\
1,10 \\
0,58 \\
0,08\end{array}$ \\
\hline Repolho & $\begin{array}{l}\text { Agosto } 96 \\
\text { Novembro } 96\end{array}$ & $\begin{array}{l}\text { Esterco de curral } \\
\text { Cama de ave } \\
\text { Termofosfato Yoorin } \\
\mathrm{KCl}+\left(\mathrm{NH}_{4}\right)_{2} \mathrm{SO}_{4(1: 1)}\end{array}$ & $\begin{array}{r}11.000 \\
3.000 \\
445 \\
468\end{array}$ & $\begin{array}{l}\text { MAQ } \\
\text { MANQ } \\
\text { AA } \\
\text { CM }\end{array}$ & $\begin{array}{l}1,32 \\
0,35 \\
0,44 \\
0,22\end{array}$ \\
\hline Pepino & $\begin{array}{l}\text { Dezembro } 96 \\
\text { Março } 97\end{array}$ & $\begin{array}{l}\text { Esterco de curral } \\
\text { Torta de mamona } \\
\text { Termofosfato Yoorin } \\
\mathrm{KCl}+\left(\mathrm{NH}_{4}\right)_{2} \mathrm{SO}_{4(1: 1)}\end{array}$ & $\begin{array}{r}40.000 \\
2.000 \\
800 \\
140\end{array}$ & $\begin{array}{l}\text { MAQ } \\
\text { MANQ } \\
\text { AA } \\
\text { CM }\end{array}$ & $\begin{array}{r}64,00 \\
44,70 \\
15,01 \\
8,38\end{array}$ \\
\hline
\end{tabular}

Fonte: Kunzmann et al. (1998).

córrego. O preparo das amostras de sedimentos foi idêntico ao adotado para amostras de solo. Próximo aos pontos onde foram coletados os sedimentos de fundo, retiraram-se amostras deágua que constaram de 10 subalíquotas de volume de $100 \mathrm{~cm}^{3}$, para compor uma amostra composta de $1 \mathrm{~L}$ de água, que foram preservadas adicionando-se $5,0 \mathrm{~mL}$ de $\mathrm{HNO}_{3}$ (65\%) (FEEMA, 1979). Para análise dos teores totais de metais pesados, $25 \mathrm{~mL}$ de água de cada amostra foram centrifugados a $10.000 \mathrm{rpm}$, por $20 \mathrm{~min}$, e, posteriormente, filtrados em "milipore" de diâmetro de 0,45 $\mu \mathrm{m}$ (FEEMA, 1979), para separação das partículas em suspensão.

Nas amostras de sol os e material de sol o perdido por erosão, dos quatrotratamentos, enos sedimentos de fundo coletados no córrego da microbacia, determinou-se o conteúdo total de metais pesados, por meio de digestão nitroperclórica, utilizando bloco de digestão e mistura de $\mathrm{HNO}_{3}+\mathrm{HClO}_{4}$ (Tedesco et al., 1997). Nos fertilizantes, adubos orgânicos, herbicidas e fungicidas utilizados no experimento, determinaram-se os teores totais, adotando-se 0 mesmo procedimento.

Os metais $\mathrm{Pb}, \mathrm{Ni}$, Zn e Mn, por apresentarem as concentrações mais el evadas nos agroquímicos utilizados na microbacia (Quadro 3), eo Cd, pela sua alta toxidez, foram sel ecionados para avaliação nas amostras de solo, sedimentos de fundo e água.
A análise granulométrica nas amostras de sol os coletadas antes do plantio e no material de solo perdido por erosão foi realizada utilizando o método da pipeta (EMBRAPA, 1997).

Com o objetivo de determinar as frações com as quais o $\mathrm{Zn}, \mathrm{Cd}, \mathrm{Pb}, \mathrm{Mn}$ e $\mathrm{Ni}$ encontravam-se predominantemente ligados no material de solo perdido por erosão, efetuou-sea extração seqüencial desses metais com $\mathrm{H}_{2} \mathrm{O}, \mathrm{NaNO}_{3}, \mathrm{NH}_{2} \mathrm{OH} \mathrm{HCl}$ (cloridrato de hidroxilamina) $0,1 \mathrm{~mol} \mathrm{~L}-1, \mathrm{NH}_{2} \mathrm{OH}$ $\mathrm{HCl} 1 \mathrm{~mol} \mathrm{~L}-1 \mathrm{eH}_{2} \mathrm{O}_{2}$, segundo Keller \& Védy (1994), conforme esquema apresentado na figura 1.

Quadro 2. Adição total de metais pesados em cada ciclo de cultura

\begin{tabular}{lrrrrr}
\hline Ciclo & Zn & Cd & $\mathbf{P b}$ & $\mathbf{M n}$ & $\mathbf{N i}$ \\
\hline & \multicolumn{5}{c}{ g ha $^{-1}$} \\
\cline { 2 - 6 } & & & & \\
Tomate & 1763 & 303 & 5.010 & 6.506 & 9.993 \\
Vagem & 2.563 & 363 & 7.013 & 6.878 & 13.046 \\
Repolho & 797 & 144 & 2.011 & 3.121 & 4.564 \\
Pepino & 2.294 & 335 & 5.839 & 6.367 & 11.848 \\
Total & 7.417 & 1.145 & 19.873 & 22.872 & 39.451 \\
\hline
\end{tabular}


Quadro 3. Conteúdo de metais pesados nos fertilizantes, adubos, herbicidas e fungicidas utilizados no experimento

\begin{tabular}{|c|c|c|c|c|c|c|c|c|}
\hline Produto & $\mathbf{P b}$ & Cd & $\mathbf{N i}$ & Co & Mn & Zn & $\mathrm{Cu}$ & $\mathbf{C r}$ \\
\hline & \multicolumn{8}{|c|}{$-\mathrm{mg} \mathrm{kg}^{-1}$} \\
\hline $\mathrm{KCl}+\left(\mathrm{NH}_{4}\right)_{2} \mathrm{SO}_{4(1: 1)}$ & 11,0 & 77,0 & 8,2 & 5,8 & 472,0 & 130,2 & 2,4 & 24,2 \\
\hline Termofosfato Yoorin & 67,2 & 4,6 & 3365,1 & 11,7 & 2504,8 & 335,6 & 44,7 & 9,3 \\
\hline Captan & 116,7 & 7,2 & 222,9 & 10,3 & 315,3 & 196,4 & 156,6 & 32,6 \\
\hline Mancozeb & 110,5 & 7,7 & 186,8 & 14,6 & 223,8 & 4,4 & 145,7 & 46,7 \\
\hline Cama de ave & 128,4 & 8,2 & 221,4 & 8,8 & 234,2 & 20,3 & 76,7 & 52,7 \\
\hline Torta de mamona & 122,4 & 7,7 & 217,3 & 8,2 & 180,6 & 47,8 & 138,9 & 65,5 \\
\hline Esterco de curral & 144,6 & 7,4 & 218,0 & 7,1 & 98,4 & 47,8 & 146,9 & 75,5 \\
\hline Tamaron BR & 50,3 & 75,1 & 7,1 & 3,6 & 9,1 & 111,0 & 2,9 & 38,6 \\
\hline Kasugamycin dorh. & 38,4 & 3,3 & 5,4 & 1,8 & 5,5 & 37,5 & 2,8 & 55,8 \\
\hline Parathion metil & 26,1 & 4,1 & 15,8 & 2,0 & 1,3 & 18,7 & 3,3 & 74,3 \\
\hline Permethrina & 45,9 & 5,2 & 8,1 & 2,6 & 1,9 & 6,8 & 5,3 & 121,1 \\
\hline
\end{tabular}

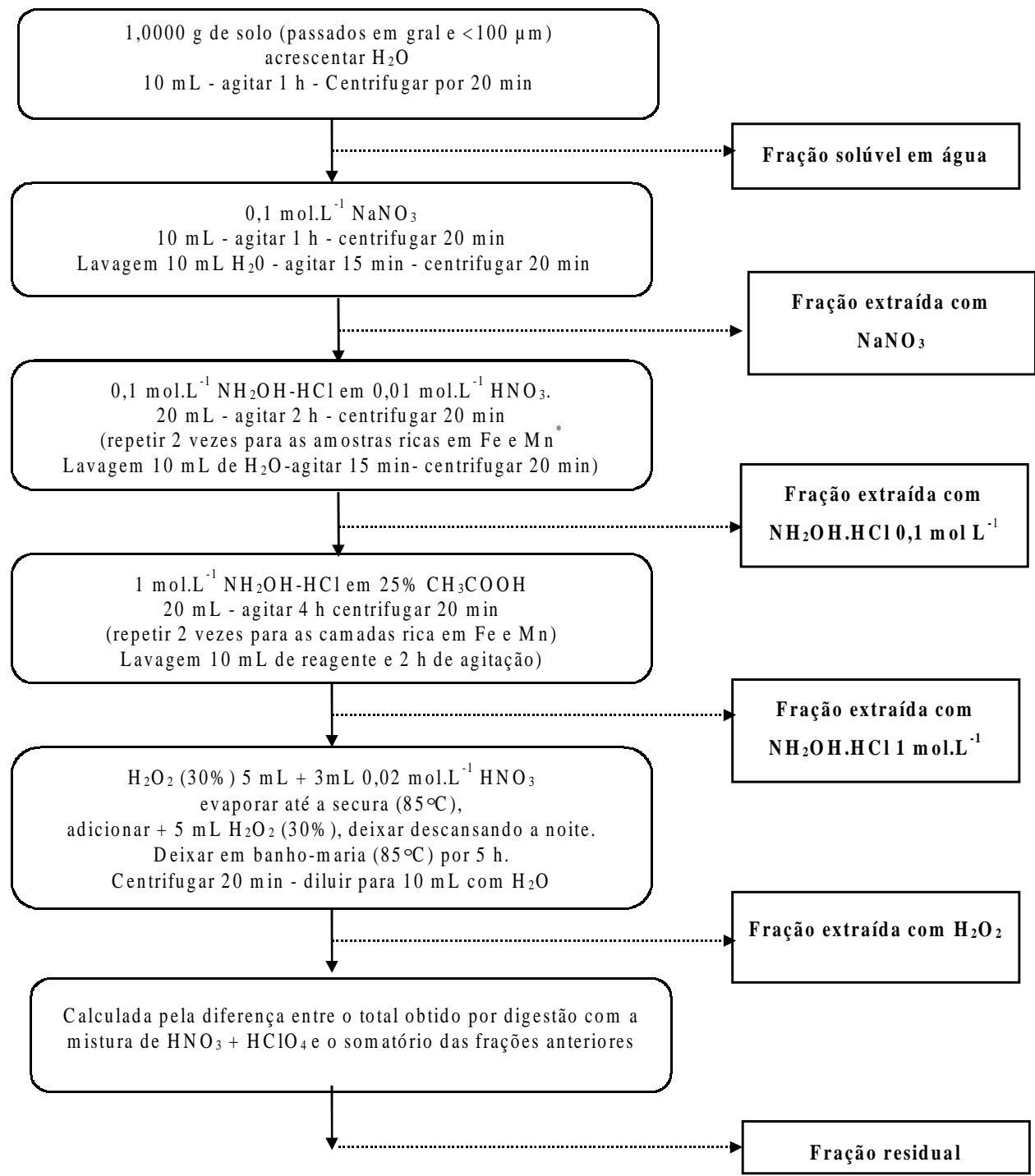

Figura 1. Esquema de Extração Seqüencial de Keller \& Védy (1994). 
As concentrações de metais pesados nos extratos da digestão de solos, sedimentos e agroquímicos, da extração seqüencial e na água, foram determinadas por espectrofotometria de absorção atômica, empregando-se chama de ar-acetileno e um equipamento VARIAN - AA600, sem correção do background.

As análises estatísticas foram realizadas com o auxílio do Programa Estatístico SAEG 5.0. O procedimento adotado para comparação de médias foi o teste Tukey a $5 \%$.

\section{RESULTADOSE DISCUSSÃO}

Vê-se, no quadro 4, a concentração total de Zn, $\mathrm{Cd}, \mathrm{Pb}, \mathrm{Mn}$ eNi nas amostras de sol o coletadas antes do plantio e depois da colheita sob os quatro sistemas de preparo. As concentrações mais el evadas desses elementos, antes do plantio, foram encontradas no tratamento CM. Como a quantidade de metais pesados aplicada por meio dos agroquímicos utilizados, durante os ciclos de tomate, vagem e repol ho (Quadro 2) foi a mesma nos quatro sistemas de preparo do solo, os teores mais altos podem ser explicados pelas menores perdas de solo por erosão observadas nesse tratamento (Quadro 1).

Comparando a concentração antes do plantio com depois da col heita, observou-se no tratamento MAQ, típico da região, redução significativa nos teores de $\mathrm{Cd}, \mathrm{Pb}, \mathrm{Mn}$ eNi. Essa redução poderia ser atribuída a perdas por lixiviação e, ou, por erosão e remoção pela cultura do pepino. Os metais pesados formam complexos muito estáveis (complexos de esfera interna) com grupos funcionais hidroxilas existentes na superfície de óxidos, oxidróxidos, hidróxidos de Fe e Mn e caulinita (Sposito, 1989) e, geralmente, nos solos intemperizados, apresentam baixa mobilidade, acumulando-se na camada superficial do sol o (Amaral Sobrinho et al., 1998). Nessesentido, como resultado da el evada perda de sol o por erosão ocorrida no sistema de preparo MAQ, no ciclo do pepino (Quadro 1), poderia levar ao empobrecimento de metais pesados acumulados na camada superficial $(0-20 \mathrm{~cm})$.

Esses resultados concordam com os obtidos por Ramalho (1996), em áreas com mais de 15 anos de olericultura na microbacia de Caetés, onde se observaram na toposseqüência de menor declividade teores mais elevados desses metais quando comparados com a de mai or declividade, justificando esses resultados pela maior erodibilidade das áreas mais declivosas.

Nos sistemas de preparo MANQ eAA (exceto para Cd), houve acumulação de metais pesados, i.e, os teores foram mais elevados após a colheita, demonstrando, possivelmente, que a quantidade removida do solo pela absorção, e princi palmente por erosão (Quadro 1), foi inferior à aplicada por meio dos agroquímicos (Quadro 2). Observou-se que os teores de $\mathrm{Zn}, \mathrm{Mn}$ e $\mathrm{Pb}$ mais elevados no sol o foram devidos à maior quantidade aplicada de agroquímicos ricos nesses metais (Quadros 2 e 3). No sistema de preparo CM, não houve alteração significativa entreas concentrações aval iadas antes e depois da colheita, demonstrando uma condição de equilíbrio entre os ganhos e as perdas de metais pesados.

O quadro 5 apresenta a concentração de Zn, Cd, $\mathrm{Pb}, \mathrm{Mn}$ e Ni total e nas diferentes formas químicas no material de solo perdido por erosão, col etado em cada sistema de preparo durante o ciclo do pepino. Demanei ra geral, a concentração total desses metais no material perdido por erosão (Quadro 5) foi inferior à analisada antes do plantio e depois da colheita (Quadro 4). No tratamento MAQ, observaram-se, para todos os elementos, concentrações totais maiores, quando comparadas com as de outros tratamentos, e os metais que apresentaram maior concentração no material de sol o perdido por erosão foram os que revelaram el evada concentração no solo antes do plantio (Quadro 4). Esses resultados vêm ratificar a hipótese feita anteriormente, ou seja, a

Quadro 4. Concentração total de metais pesados em amostras de solo coletadas antes do plantio e depois da colheita do pepino nos quatro sistemas de preparo(1)

\begin{tabular}{|c|c|c|c|c|c|c|c|c|c|c|}
\hline Preparo do solo & $\mathbf{A P}(2)$ & $D C^{(3)}$ & AP & DC & AP & DC & AP & DC & AP & DC \\
\hline & \multicolumn{10}{|c|}{$-\mathrm{mg} \mathrm{kg}^{-1}$} \\
\hline MAQ & $32,95 \mathrm{bB}$ & $39,42 \mathrm{bA}$ & 3,65 aA & $1,90 \mathrm{bB}$ & $32,30 \mathrm{aA}$ & $25,00 \mathrm{bB}$ & $48,02 \mathrm{aA}$ & 39,02 bB & $6,11 \mathrm{bA}$ & $4,55 \mathrm{bB}$ \\
\hline MANQ & $15,58 \mathrm{cB}$ & $40,31 \mathrm{bA}$ & $1,56 \mathrm{bB}$ & $2,79 \mathrm{aA}$ & $23,50 \mathrm{bB}$ & 31,64 aA & $24,87 c B$ & $37,27 \mathrm{bA}$ & $3,98 \mathrm{cB}$ & 7,36 aA \\
\hline AA & $38,83 \mathrm{bB}$ & $41,89 \mathrm{bA}$ & $2,15 \mathrm{bA}$ & $2,64 \mathrm{aA}$ & $28,03 \mathrm{bB}$ & $31,72 \mathrm{aA}$ & 31,42 bB & $38,15 \mathrm{bA}$ & $6,16 \mathrm{bB}$ & $8,20 \mathrm{aA}$ \\
\hline $\mathrm{CM}$ & $46,95 \mathrm{aA}$ & $47,88 \mathrm{aA}$ & 3,16 aA & $2,48 \mathrm{aB}$ & $33,06 \mathrm{aA}$ & $28,89 \mathrm{bA}$ & $47,27 \mathrm{aA}$ & $46,71 \mathrm{aA}$ & 8,61 aA & 9,46 aA \\
\hline
\end{tabular}

(1) Médias seguidas da mesma letra maiúscula, na linha, e pela mesma letra minúscula, na coluna, para cada elemento, não diferem entre si pelo teste de Tukey a 5\%. ${ }^{(2)}$ Amostra coletada no solo antes do plantio. ${ }^{(3)}$ Amostra coletada no solo depois da col heita. 
perda de $\mathrm{Cd}, \mathrm{Ni}, \mathrm{Pb}$, e $\mathrm{Mn}$ por erosão contribuiu para redução da concentração desses el ementos no solo depois da col heita do pepino.

A concentração total dos metais pesados não permite uma aval iação completa do possível impacto ambiental, por isso, para avaliar o seu potencial tóxico, realizou-se extração seqüencial nas amostras compostas do material de solo perdido por erosão, coletadas durante o cicl o do pepino. Verificou-se, nos quatro sistemas de preparo, que os metais pesados estavam distribuídos, predominantemente, nas frações residuais e extraídas com $\mathrm{NH}_{2} \mathrm{OH} \mathrm{HCl}$ (cloridrato de hidroxilamina). O Cd e o $\mathrm{Mn}$ apresentaram percentagens nas frações extraíveis $\mathrm{com} \mathrm{H}_{2} \mathrm{O}$ e NaNO${ }_{3}$ superiores às de outros el ementos, o que, dependendo do mau uso continuado desses solos e do acúmulo de metais pesados pelo uso intensivo de agroquímicos, poderia favorecer a contaminação da água e a introdução desses elementos na cadeia alimentar (Pardo et al., 1990). Ramalho(1996), realizando extração seqüencial em amostras de solo da microbacia de Caetés, Paty do Alferes-RJ , encontrou, em áreas com mais de 15 anos de intensa atividade olerícola, concentrações mais el evadas de $\mathrm{Zn}, \mathrm{Mn}, \mathrm{Cd}$ e $\mathrm{Pb}$ do que em áreas com atividade mais recente, verificando também que esses metais, em sua maioria, estavam ligados, predominantemente, às frações extraídas com $\mathrm{NH}_{2} \mathrm{OH} \mathrm{HCl}$ (cloridrato de hidroxilamina).

A composição granulométrica do solo antes do plantio e no material perdido por erosão nos quatro sistemas de preparo é apresentada no quadro 6. Verifica-se no material perdido por erosão redução da fração argila, com conseqüente aumento da fração areia. Resultados semel hantes foram encontrados por Martins Filho \& Silva (1985), avaliando a composição granulométrica do material de solo perdido por erosão de um Latossolo VermelhoAmarel odistrófico, emU bajara (CE). Eles verificaram que as principais frações perdidas por erosão nesses solos corresponderam à fração silte e areia. Esses resultados poderiam explicar, em parte, a menor concentração desses metais no material perdido por erosão, considerando a alta afinidade entre esses elementos e a fração argila (Alloway, 1990). O tratamento MAQ, por causar maior revolvimento do solo (Carvalho et al., 1997), apresentou teor mais el evado da fração argila comparado com o de outros

Quadro 5. Concentração total de metais nas diferentes formas químicas no material de solo perdido por erosão no ciclo do pepino nos quatro sistemas de preparo(1)

\begin{tabular}{|c|c|c|c|c|c|c|c|}
\hline \multirow{2}{*}{ Preparo do solo } & \multicolumn{7}{|c|}{ Frações } \\
\hline & $\mathrm{H}_{2} \mathrm{O}$ & $\mathrm{NaNO}_{3}$ & $\mathrm{NH}_{2} \mathrm{OH} \mathrm{HCl} \mathrm{0,1} \mathrm{mol}^{-1}$ & $\mathrm{NH}_{2} \mathrm{OH} \mathrm{HCl} \mathrm{1,0} \mathrm{\textrm {mol } ^ { - 1 }}$ & $\mathbf{H}_{2} \mathbf{O}_{2}$ & Residual & Total \\
\hline & \multicolumn{7}{|c|}{$\mathrm{mg} \mathrm{kg}^{-1}$} \\
\hline \multicolumn{8}{|c|}{ Zinco } \\
\hline $\begin{array}{l}\text { MAQ } \\
\text { MANQ } \\
\text { AA } \\
\text { CM }\end{array}$ & $\begin{array}{l}0,64 \mathrm{a} \\
0,31 \mathrm{c} \\
0,57 \mathrm{a} \\
0,44 \mathrm{~b}\end{array}$ & $\begin{array}{l}1,98 \mathrm{a} \\
0,69 \mathrm{~b} \\
1,34 \mathrm{a} \\
0,76 \mathrm{~b}\end{array}$ & $\begin{array}{l}8,53 a \\
3,67 b \\
7,65 a \\
6,20 a\end{array}$ & $\begin{array}{l}5,56 \mathrm{a} \\
2,56 \mathrm{~b} \\
4,42 \mathrm{a} \\
2,82 \mathrm{~b}\end{array}$ & $\begin{array}{l}8,96 \mathrm{a} \\
3,98 \mathrm{c} \\
6,59 \mathrm{~b} \\
4,88 \mathrm{c}\end{array}$ & $\begin{array}{l}21,70 \mathrm{a} \\
10,39 \mathrm{c} \\
16,06 \mathrm{~b} \\
11,40 \mathrm{c}\end{array}$ & $\begin{array}{l}47,37 \mathrm{a} \\
21,61 \mathrm{c} \\
36,63 \mathrm{~b} \\
26,50 \mathrm{c}\end{array}$ \\
\hline \multicolumn{8}{|c|}{ Cádmio } \\
\hline $\begin{array}{l}\text { MAQ } \\
\text { MANQ } \\
\text { AA } \\
\text { CM }\end{array}$ & $\begin{array}{l}0,09 \mathrm{a} \\
0,01 \mathrm{~b} \\
0,03 \mathrm{~b} \\
0,08 \mathrm{a}\end{array}$ & $\begin{array}{l}0,08 \mathrm{a} \\
0,01 \mathrm{~b} \\
0,03 \mathrm{~b} \\
0,07 \mathrm{a}\end{array}$ & $\begin{array}{l}0,01 \mathrm{a} \\
0,02 \mathrm{a} \\
0,01 \mathrm{a} \\
0,01 \mathrm{a}\end{array}$ & $\begin{array}{l}0,01 \text { a } \\
0,02 \text { a } \\
0,01 \text { a } \\
0,01 \text { a }\end{array}$ & $\begin{array}{l}0,03 \mathrm{a} \\
0,00 \mathrm{~b} \\
0,01 \mathrm{~b} \\
0,04 \mathrm{a}\end{array}$ & $\begin{array}{l}0,42 \mathrm{a} \\
0,04 \mathrm{c} \\
0,18 \mathrm{~b} \\
0,38 \mathrm{a}\end{array}$ & $\begin{array}{l}0,64 \mathrm{a} \\
0,10 \mathrm{c} \\
0,27 \mathrm{~b} \\
0,59 \mathrm{a}\end{array}$ \\
\hline \multicolumn{8}{|c|}{ Chumbo } \\
\hline $\begin{array}{l}\text { MAQ } \\
\text { MANQ } \\
\text { AA } \\
\text { CM }\end{array}$ & $\begin{array}{l}0,60 \mathrm{a} \\
0,43 \mathrm{~b} \\
0,62 \mathrm{a} \\
0,43 \mathrm{~b}\end{array}$ & $\begin{array}{l}0,57 \mathrm{a} \\
0,42 \mathrm{~b} \\
0,63 \mathrm{a} \\
0,42 \mathrm{~b}\end{array}$ & $\begin{array}{l}1,67 \mathrm{a} \\
1,08 \mathrm{~b} \\
1,76 \mathrm{a} \\
1,58 \mathrm{a}\end{array}$ & $\begin{array}{l}3,38 \mathrm{a} \\
2,17 \mathrm{~b} \\
3,54 \mathrm{a} \\
3,20 \mathrm{a}\end{array}$ & $\begin{array}{l}2,11 \mathrm{a} \\
1,47 \mathrm{~b} \\
2,29 \mathrm{a} \\
1,87 \mathrm{ab}\end{array}$ & $\begin{array}{l}7,02 \mathrm{a} \\
4,83 \mathrm{~b} \\
3,94 \mathrm{~b} \\
3,47 \mathrm{~b}\end{array}$ & $\begin{array}{l}15,34 \mathrm{a} \\
10,40 \mathrm{~b} \\
12,78 \mathrm{~b} \\
10,98 \mathrm{~b}\end{array}$ \\
\hline \multicolumn{8}{|c|}{ Manganês } \\
\hline $\begin{array}{l}\text { MAQ } \\
\text { MANQ } \\
\text { AA } \\
\text { CM }\end{array}$ & $\begin{array}{l}1,54 \mathrm{~b} \\
1,25 \mathrm{~b} \\
1,52 \mathrm{~b} \\
2,23 \mathrm{a}\end{array}$ & $\begin{array}{l}2,03 \mathrm{a} \\
1,46 \mathrm{~b} \\
1,68 \mathrm{~b} \\
1,53 \mathrm{~b}\end{array}$ & $\begin{array}{l}9,02 \mathrm{a} \\
5,09 \mathrm{~b} \\
7,12 \mathrm{ab} \\
8,14 \mathrm{a}\end{array}$ & $\begin{array}{l}1,85 \mathrm{a} \\
0,78 \mathrm{~b} \\
1,09 \mathrm{~b} \\
1,79 \mathrm{a}\end{array}$ & $\begin{array}{l}0,97 \mathrm{a} \\
0,51 \mathrm{~b} \\
0,71 \mathrm{ab} \\
0,94 \mathrm{a}\end{array}$ & $\begin{array}{r}9,67 \mathrm{a} \\
6,89 \mathrm{~b} \\
8,52 \mathrm{a} \\
10,20 \mathrm{a}\end{array}$ & $\begin{array}{l}25,08 \mathrm{a} \\
15,97 \mathrm{~b} \\
20,64 \mathrm{a} \\
24,83 \mathrm{a}\end{array}$ \\
\hline \multicolumn{8}{|c|}{ Níquel } \\
\hline $\begin{array}{l}\text { MAQ } \\
\text { MANQ } \\
\text { AA } \\
\text { CM }\end{array}$ & $\begin{array}{l}0,03 \mathrm{a} \\
0,00 \mathrm{~b} \\
0,05 \mathrm{a} \\
0,04 \mathrm{a}\end{array}$ & $\begin{array}{l}0,05 \mathrm{a} \\
0,00 \mathrm{~b} \\
0,03 \mathrm{ab} \\
0,01 \mathrm{~b}\end{array}$ & $\begin{array}{l}0,02 \mathrm{~b} \\
0,00 \mathrm{~b} \\
0,05 \mathrm{a} \\
0,04 \mathrm{a}\end{array}$ & $\begin{array}{l}0,64 \mathrm{a} \\
0,01 \mathrm{c} \\
0,73 \mathrm{a} \\
0,46 \mathrm{~b}\end{array}$ & $\begin{array}{l}0,50 \mathrm{a} \\
0,01 \mathrm{c} \\
0,55 \mathrm{a} \\
0,36 \mathrm{~b}\end{array}$ & $\begin{array}{l}2,10 \mathrm{a} \\
0,04 \mathrm{c} \\
2,33 \mathrm{a} \\
1,47 \mathrm{~b}\end{array}$ & $\begin{array}{l}3,34 \mathrm{a} \\
0,07 \mathrm{c} \\
3,73 \mathrm{a} \\
2,39 \mathrm{~b}\end{array}$ \\
\hline
\end{tabular}

(1) Médias seguidas da mesma letra minúscula, na coluna, para cada elemento, não diferem entre si pelo teste de Tukey a 5\%. 
tratamentos, contribuindo, dessa forma, para a maior perda por erosão desses metais que interagem fortemente com a superfície de óxidos, oxidróxidos, hidróxi dos e caul inita presentes nessa fração do solo. Sabri et al. (1993), estudando a natureza dos sedimentos do rioTigris, no I raque, encontraram as mais altas concentrações de $\mathrm{Zn}, \mathrm{Pb}$ e Ni, quando a argila era o componente dominante; entretanto, quando a areia ou silte eram os principais componentes, a concentração dos metais foi menor .

No sistema de preparo MAQ, concentrações mais el evadas de $\mathrm{Zn}, \mathrm{Cd}, \mathrm{Pb}, \mathrm{Mn}$ e Ni no material de solo perdido por erosão (Quadro 5), juntamente com a maior quantidade de solo perdida (Quadro 1), determinaram quantidades el evadas de perdas por erosão desses metais (Quadro 7). A perda de Zn, Cd, $\mathrm{Pb}, \mathrm{Mn}$, e Ni no tratamento MAQ foi cerca de 14,8 , 11,8 e 11 vezes superior, respectivamente, ao sistema CM. Os sistemas de preparo MANQ e AA também apresentaram perdas bem menores, quando comparadas às do sistema típico de preparo do solo da região MAQ. É importante ressaltar que essas quantidades referem-se apenas ao ciclo do pepino de aproximadamente três meses.

Considerando que, na região, o período de maior precipitação concentra-se de setembro a março (Marques et al., 1998), as perdas poderiam ser mais el evadas em um ano agrícola compl eto da região sob esse sistema de preparo do solo e quantidades de insumos utilizados. Outro dado que deve ser analisado éa percentagem desses metais nas frações extraíveis com $\mathrm{H}_{2} \mathrm{O}$ e $\mathrm{NaNO}_{3}$ do material perdido por erosão, consideradas de maior mobilidade e biodisponibilidade (Keller \& Védy, 1994). A soma das percentagens de $\mathrm{Zn}, \mathrm{Cd}, \mathrm{Pb}, \mathrm{Mn}$ e Ni nessas frações é de $5,6,26,5,7,6,14,2$, e 2,4\%, correspondendo a uma perda de 170, 11, 75, 228 e $5 \mathrm{~g} \mathrm{ha}^{-1}$, respectivamente. Não se pode descartar a possibilidade de os metais ligados às frações extraíveis com cloridrato de hidroxilamina (predominante) atingirem o ambienteaquático. Sob condições redutoras, poderão ter a solubilidade aumentada e, conseqüentemente, maior será o impacto das perdas desses metais por erosão (van Put et al., 1994).

O quadro 7 também fornece informações da percentagem do total do metal aplicado no ciclo do pepino que foi perdida por erosão. Observaram-se para Zn perdas superiores ao total aplicado no ciclo do pepino (Quadro 2) no tratamento MAQ. O CM minimizou as perdas dos metais pesados por erosão, tendo sido cerca de apenas $10 \%$ do total aplicado desse elemento perdido, reduzindo os riscos de contaminação da água do córrego que atravessa a

Quadro 6. Composição granulométrica do solo antes do plantio e no material perdido por erosão nos quatro sistemas de preparo do solo ${ }^{(1)}$

\begin{tabular}{|c|c|c|c|c|c|c|c|c|}
\hline \multirow{2}{*}{ Preparo do solo } & \multicolumn{2}{|c|}{ Areia total } & \multicolumn{2}{|c|}{ Areia grossa } & \multicolumn{2}{|c|}{ Silte } & \multicolumn{2}{|c|}{ Argila total } \\
\hline & $A P^{(2)}$ & $E r^{(3)}$ & AP & Er & AP & $\mathbf{E r}$ & AP & Er \\
\hline $\begin{array}{l}\text { MAQ } \\
\text { MANQ } \\
\text { AA } \\
\text { CM }\end{array}$ & $\begin{array}{l}500 \mathrm{aB} \\
460 \mathrm{bB} \\
480 \mathrm{bB} \\
480 \mathrm{bB}\end{array}$ & $\begin{array}{l}600 \mathrm{aA} \\
600 \mathrm{aA} \\
600 \mathrm{aA} \\
660 \mathrm{aA}\end{array}$ & $\begin{array}{l}130 \mathrm{aA} \\
140 \mathrm{aA} \\
140 \mathrm{aA} \\
130 \mathrm{aA}\end{array}$ & $\begin{array}{r}110 \mathrm{aA} \\
120 \mathrm{aA} \\
130 \mathrm{aA} \\
80 \mathrm{bB}\end{array}$ & $\begin{array}{l}100 \mathrm{aA} \\
100 \mathrm{aA} \\
110 \mathrm{aA} \\
120 \mathrm{aA}\end{array}$ & $\begin{array}{l}30 \mathrm{bB} \\
60 \mathrm{aB} \\
50 \mathrm{aB} \\
50 \mathrm{aB}\end{array}$ & $\begin{array}{l}400 \mathrm{bA} \\
440 \mathrm{aA} \\
410 \mathrm{bA} \\
400 \mathrm{bA}\end{array}$ & $\begin{array}{l}370 \mathrm{aB} \\
340 \mathrm{bB} \\
350 \mathrm{bB} \\
290 \mathrm{cB}\end{array}$ \\
\hline
\end{tabular}

(1) Médias seguidas da mesma letra maiúscula, na linha, e letra minúscula, na coluna, para cada fração granulométrica, não diferem entre si pelo teste de Tukey a 5\%. ${ }^{(2)}$ Teor no solo antes do plantio. ${ }^{(3)}$ Teor no material de solo perdido por erosão.

Quadro 7. Perda total de metais pesados por erosão, no ciclo do pepino, nos quatro sistemas de preparo do solo ${ }^{(1)}$

\begin{tabular}{lccccc}
\hline Preparo & $\mathbf{Z n}$ & $\mathbf{C d}$ & $\mathbf{P b}$ & $\mathbf{M n}$ & $\mathbf{N i}$ \\
\hline & & & $\mathrm{g} \mathrm{kg}^{-1}$ & & \\
MAQ & $3.033 \mathrm{a}(132)^{(2)}$ & $40 \mathrm{a}(11,9)$ & $982 \mathrm{a}(16,81)$ & $1.604 \mathrm{a}(25,19)$ & $214 \mathrm{a}(1,8)$ \\
MANQ & $965 \mathrm{~b}(42)$ & $4 \mathrm{~b}(1,2)$ & $465 \mathrm{~b}(7,96)$ & $714 \mathrm{~b}(11,21)$ & $3 \mathrm{~d}(0,02)$ \\
AA & $550 \mathrm{c}(23,98)$ & $4 \mathrm{~b}(1,2)$ & $192 \mathrm{c}(3,29)$ & $309 \mathrm{c}(4,80)$ & $56 \mathrm{~b}(0,47)$ \\
CM & $222 \mathrm{~d}(9,67)$ & $5 \mathrm{~b}(1,5)$ & $93 \mathrm{~d}(1,6)$ & $208 \mathrm{~d}(3,27)$ & $20 \mathrm{c}(0,17)$
\end{tabular}

(1) Médias seguidas da mesma letra minúscula, na mesma coluna, não diferem entre si pel o teste de Tukey a 5\%. ${ }^{(2)}$ Os números entre parênteses representam a percentagem de perda do total do metal aplicado no ciclo do pepino. 


\section{Quadro 8. Teores totais de $\mathrm{Zn}, \mathrm{Cd}, \mathrm{Pb}, \mathrm{Mn}$ e $\mathrm{Ni}$, em amostras de sedimentos de fundo e da água do córrego da microbacia de Caetés/Paty do Alferes (RJ $)^{(1)}$}

\begin{tabular}{|c|c|c|c|c|c|}
\hline Local & $\mathbf{Z n}$ & Cd & $\mathbf{P b}$ & Mn & $\mathbf{N i}$ \\
\hline & \multicolumn{5}{|c|}{ Sedimentos } \\
\hline & & & $\mathrm{mg} \mathrm{kg}^{-1}$ & & \\
\hline Córrego $1^{(2)}$ & $25,9 \mathrm{c}$ & $0,26 \mathrm{c}$ & $13,92 \mathrm{~b}$ & $29,68 \mathrm{c}$ & $7,33 \mathrm{c}$ \\
\hline Córrego $2^{(3)}$ & $449,4 \quad a$ & $0,62 b$ & $29,42 \mathrm{a}$ & 360,5 a & $14,38 \mathrm{~b}$ \\
\hline \multirow[t]{3}{*}{ Açude ${ }^{(4)}$} & $66,42 \mathrm{~b}$ & $0,82 a$ & $29,02 a$ & $116,1 \quad b$ & $15,37 \mathrm{a}$ \\
\hline & \multicolumn{5}{|c|}{ Água } \\
\hline & & & $-m g L^{-1}$ & & \\
\hline Córrego 1 & $0,34 \mathrm{c}$ & $0,11 \mathrm{~b}$ & $0,02 \mathrm{c}$ & $0,23 c$ & $0,65 a$ \\
\hline Córrego 2 & $0,90 \mathrm{~b}$ & $0,14 a$ & $0,08 \mathrm{a}$ & $0,72 \mathrm{a}$ & $0,66 \mathrm{a}$ \\
\hline Açude & $1,70 \mathrm{a}$ & $0,09 c$ & $0,06 \mathrm{~b}$ & $0,33 \mathrm{~b}$ & $0,46 \mathrm{~b}$ \\
\hline Concentração máxima(5) & 5,0 & 0,005 & 0,05 & 0,10 & - \\
\hline
\end{tabular}

(1) Médias seguidas da mesma letra minúscula, na coluna, não diferem entre si pelo teste de Tukey a 5\%. ${ }^{(2)}$ Amostras de água e sedimentos coletadas à montante da área agrícola atual de olericultura. ${ }^{(3)}$ Amostras de água e sedimentos coletadas à jusante da área agrícola atual de olericultura. ${ }^{(4)}$ Amostras de água e sedimentos coletadas no açude. ${ }^{(5)}$ Concentrações máximas permitidas para água potável segundo BRASI L,... Ministério da Saúde (1990).

microbacia. Esses resultados demonstram, deforma inequívoca, que a utilização na mi crobacia de outro sistema de preparo do solo, como o cultivo mínimo ou aração com tração animal, em nível, levaria a uma redução sensível dos impactos ao ambiente pelas perdas por erosão.

A análise dos sedimentos de rios tem sido usada como indicador da poluição por metais pesados pela sua habilidade de integrar as descargas liberadas no agroecossistema (Lacerda et al., 1993; Bubb \& Lester, 1994). No quadro 8, observou-se que as amostras retiradas no córrego 2, na posi ção de maior influência das áreas cultivadas, assim como as amostras col etadas no açude, apresentaram aumentos estatisticamente significativos dos teores de $\mathrm{Zn}, \mathrm{Cd}, \mathrm{Pb}, \mathrm{Mn}$ e Ni, quando comparados aos das amostras retiradas do córrego na posição à montante da área de olericultura (córrego 1), com destaque para os aumentos nos teores de $\mathrm{Zn}$ e $\mathrm{Mn}$ com incrementos de quase $200 \%$. Os teores totais de metais pesados nas amostras de água (Quadro 8) revelaram val ores significativamente mais elevados de $\mathrm{Zn}, \mathrm{Cd}, \mathrm{Pb}$ e $\mathrm{Mn}$ nas amostras col etadas à jusante da área de ol ericultura atual do córrego da microbacia (córrego 2) e no açude, tendo um comportamento semelhante ao observado para os sedimentos.

As concentrações de $\mathrm{Cd}, \mathrm{Pb}$ e $\mathrm{Mn}$, quando comparadas com os padrões de potabilidade de água estabelecidos pelo Ministério da Saúde (1990), ficaram acima do permitido, mostrando enriquecimento dos teores desses metais de acordo com o local de coleta. Portanto, os resultados encontrados para sedimentos e água estão em conformidade com os obtidos das quantidades perdidas de $\mathrm{Zn}, \mathrm{Mn}$ e Pb por erosão, principalmente no sistema de preparo MAQ, típico da região, demonstrando que os agroquímicos com metais pesados, associados às el evadas perdas por erosão, podem determinar sérios riscos de contami nação da água do córrego da microbacia queé utilizada pelos animais e para irrigação.

\section{CONCLUSÕES}

1. O sistema de preparo aração morro abaixo e restos vegetais queimados (MAQ), típico da região, por provocar maiores perdas por erosão, acarretou perdas el evadas de $\mathrm{Cd}, \mathrm{Ni}, \mathrm{Pb}, \mathrm{Zn}$ e M n; entretanto, os sistemas de preparo cultivo mínimo (CM) earação com tração animal (AA) reduziram as perdas por erosão desses metais.

2. A utilização na microbacia de outro sistema de preparo do solo, como o cultivo mínimo ou aração com tração animal, em nível, levaria a uma redução sensível dos impactos ao ambiente.

3. O uso intensivo de agroquími cos e as el evadas perdas de solo por erosão podem determinar sérios riscos de contaminação da água do córrego da microbacia que é utilizada pelos animais e para irrigação. 


\section{LITERATURA CITADA}

ALLOWAY, B.J. The origins of heavy metals in soils. In: ALLOWAY, B.J ., ed. Heavy metals in soils. New York, J ohn Wiley, 1990. p.29-39.

AMARAL SOBRINHO, N.M.B.; COSTA, L.M.; OLIVEIRA, C. \& VELLOSO, A.C.X. Metais pesados em alguns fertilizantes e corretivos. R. Bras. Ci. Solo, 16:271-276, 1992.

AMARAL SOBRINHO, N.M.B.; VELLOSO, A.C.X.; COSTA, L.M. $\&$ OLIVEIRA, C. Mobilidade de metais pesados em solo tratado com resíduo siderúrgico ácido. R. Bras. Ci. Solo, 22:345-353, 1998.

BLUME, H.P. \& BRÜMMER, G. Predictions of heavy metals behavior in soil by means of simple field test. E cotoxicol. Environ. Saf., 22:164-174, 1991.

BRASI L. Ministério da Saúde. Normas e padrão de potabilidade de água destinada ao consumo humano. Portaria 6M/36/ 1990. Brasília, 1990.

BUBB, J .M. \& LESTER, J .N. Anthropogenic heavy metal inputs tolowland river systems, a case study. Theriver Stour, U.K. Water Soil Poll., 78:279-296, 1994.

CARVALHO, M.P.; CATANEO, A. \& LOMBARDI NETO, F. Parâmetros de erosividade da chuva e da enxurrada correlacionados com as perdas de solo e determinação da erodibilidade de um Podzólico Vermelho-Amarelo de Pindorama. R. Bras. Ci. Solo, 21:279-286, 1997.

EMPRESA BRASILEIRA DE PESQUISA AGROPECUÁRIA EMBRAPA. Centro Nacional de Pesquisa de Solos. Manual de métodos de análise de solo. 2.ed. Rio de J aneiro, 1997. $212 p$.

FUNDAÇÃO ESTADUAL DE ENGENHARIA DO MEIO AMBIENTE - FEEMA. Manual do meio ambiente. Rio de J aneiro, 1979. 126p.

FRANK, R.; ISHIDA, K.\& SUDA, P. Metals in agricultural soils of Ontario. Can. J. Soil Sci., 56:181-196, 1976.

GIMENO-GARCIA, E.; ANDREU, V. \& BOLUDA, R. Heavy metals incidence in the application of organic fertilizers and pesticides to rice farming soils. Environ. Poll., 92:1925, 1996.

GRAVENA, S.; BENVENGA, S.; ABREU, H..; GROPPO, B.; ZANDER, R.; KLEIN-GUNNEWIEK, R. Manejo Ecológico de pragas e doenças do tomate envarado. In: CONFERÊNCIA INTERNACIONAL DE AGRICULTURA SUSTENTÁVEL EM REGIÕES MONTANHOSAS TROPICAIS E SUBTROPICAIS COM ESPECIAL REFERÊNCIA PARA A AMÉRICA LATINA., Rio de J aneiro, 1998. Resumos. Rio de J aneiro, 1998. p.53.
KABATA-PENDIAS, A. \& PENDIAS, H. Trace elements in soils and plants. Boca Raton, CRC Press, 1984. 315p.

KELLER, C. \& VÉDY,J.C. Distribution of copper and cadmium fractions in two forest soils. J. Environ. Qual., 23:987999,1994

KUNZMANN, M.; PRINZ, D.; PALMIERI, F.; NÚNEZ, J .E.V.; GOUVEIA, R. \& COELHO, R.G. Evaluation of soil losses for different soil management practices in the municipality of Paty do Alferes, RJ - an aspect of the DESUSMO project. In: CONFERENCIA INTERNACIONAL DE AGRICULTURA SUSTENTÁVEL EM REGIÕES MONTANHOSAS TROPICAIS E SUBTROPICAIS COM ESPECIAL REFERÊNCIA PARA A AMÉRICA LATINA., Rio de J aneiro, 1998. Resumos. Rio de J aneiro, 1998. p.29.

LACERDA, L.D. Heavy metal pollution in soil and plants of the I rajá river estuarine area in the Guanabara bay. R. Bras. Biol., 42:89-93, 1982.

MARQUES, J. \& PINHEIRO, F.M.A. Características hidrometereológicas de Paty do Alferes, RJ. In: CONFERÊNCIA INTERNACIONAL DE AGRICULTURA SUSTENTÁVEL EM REGIÕES MONTANHOSAS TROPICAIS E SUBTROPICAIS COM ESPECIAL REFERÊNCIA PARA A AMÉRICA LATINA, Rio deJ aneiro, 1998. Resumos. Rio de J aneiro, 1998. p.31.

MARTINS FILHO, E.C. \& SILVA, J .R.C. Comparação demétodos de avaliação da erodibilidade em Latossolo VermelhoAmarelo distrófico. R. Bras. Ci. Solo, 9:175-178, 1985.

PARDO, R.; BARRADO, E.; PEREZ, L. \& VEGA, M. Determination and speciation of heavy metals in sediments of the Pisuerga river. Water Res., 24:373-379, 1990.

RAMALHO, J .F.G. Metais pesados em solos com diferentes usos agrícolas no estado do Rio de J aneiro. Seropédica, Universidade Federal Rural do Rio deJ aneiro, 1996. 160p. (Tese de Doutorado)

SABRI, A.W.; RASHEED, K.A. \& KASSIM, T.I. Heavy metals in the water, suspended solids and sediments of the river Tigris impoundment at Samarra. Water Res., 27:1099-1103, 1993.

SPOSITO, G. The chemistry of soils. New York, Oxford U niversity Press, 1989. 234p.

TEDESCO, M.J .; GIANELLO, C.; BISSANI,C.A.; BOHNEN, H. \& VOLKWEISS, S.J. Análise de solo, plantas e outros materiais. 2.ed. Porto Alegre, Universidade Federal do Rio Grande do Sul, 1997. 174p.

TILLER, K.G. Heavy metals in soils and their environmental significance. Adv. Soil Sci., 9:113-142, 1989.

van PUT, A.; van GRIEKEN, R. WILKEN, R.D. \& HUDEC, B. Geochemical characterization of suspended matter and sediment samples from the Elbe river by EPXMA. Water Res., 28:643-655, 1994. 